\title{
Response of Permafrost Thermal Regime to Climate Change over Northern Hemisphere in the 21st Century
}

\author{
Wenhao Yang, Hongxia Shi* \\ School of Atmospheric Sciences, Chengdu University of Information Technology, Chengdu, China \\ Email: ^573947530@qq.com
}

How to cite this paper: Yang, W. H., \& Shi, H. X. (2021). Response of Permafrost Thermal Regime to Climate Change over Northern Hemisphere in the 21st Century. Journal of Geoscience and Environment Protection, 9, 87-101.

https://doi.org/10.4236/gep.2021.99006

Received: September 3, 2021

Accepted: September 25, 2021

Published: September 28, 2021

Copyright $\odot 2021$ by author(s) and Scientific Research Publishing Inc. This work is licensed under the Creative Commons Attribution International License (CC BY 4.0).

http://creativecommons.org/licenses/by/4.0/

\begin{abstract}
Based on the CMIP5 simulation and numerical model, the permafrost thermal regimes over Northern Hemisphere land during the early (2016-2035), middle (2046-2065) and late (2080-2099) period of 21st century are projected, and its relationship with climate change is also analyzed. The results show that, relative to the reference period of 1986-2005, the mean annual ground temperature (MAGT) over Northern Hemisphere shows an increasing trend, with a decreasing trend of the depth of zero annual amplitude (DZAA), and the most significant changes occur in Siberia, Tibetan Plateau, Canada arctic and Alaska, and the changes in MAGT and DZAA grow larger with time and emission, especially during the LP for RCP8.5, MAGT will increase by $4^{\circ} \mathrm{C}$ and DZAA decreases by $1.5 \mathrm{~m}$ (the relative change exceeds $20 \%$ ) in most regions. The changes of permafrost in the 21st century mainly depend on the changes of cold permafrost. The relationship between MAGT and air temperature as well as that between DZAA and air temperature suggests that the increase of MAGT and the decrease of DZAA are related to the increase of air temperature in winter, especially in January. However, the rate of change in MAGT and DZAA gradually declines, with the temperature increasing.
\end{abstract}

\section{Keywords}

CMIP5, Permafrost, Mean Annual Ground Temperature, Depth of Zero Annual Amplitude

\section{Introduction}

Permafrost is a product of cold climate. It is highly sensitive to climate change and has experienced wide degradation during the last several decades in Russian European North (Oberman, 2008), Northern Norway (Farbrot et al., 2013), 
north-western Russian (Drozdov et al., 2010), northern Alaska (Ling \& Zhang, 2003), and Qinghai-Xizang Plateau (Qin et al., 2006), but this response is complex and various throughout these permafrost regions. Permafrost degradation and warming may affect the local hydrology, ecology, engineering infrastructure, as well as carbon dioxide and methane fluxes, even the climate (Zimov et al., 2006). Therefore, its roles of permafrost in the atmosphere and land interaction have been increasingly recognized, especially recently (Nelson et al., 2003).

Global air temperature has increased since the late 1800s and the temperature rising is expected to be amplified in the Arctic and sub-Arctic, which accelerates the changes of permafrost warming and degradation (Oberman, 2008). Permafrost thermal regime is an excellent indicator and integrator of climate change (Osterkamp, 2005), recent assessment of the permafrost thermal regime suggests an ongoing warming over most parts of permafrost regions (Romanovsky et al., 2007), however, the response may be complex and discordances (Wu et al., 2012). In Russia, most measured ground temperature shows a substantial warming during the last 20 to 30 years, and the increasing magnitude of mean annual ground temperature (MAGT) ranges from $0.5^{\circ} \mathrm{C}$ to $2^{\circ} \mathrm{C}$ (Romanovsky et al., 2010) in Northern Norway, the present permafrost mainly belongs to warm permafrost, with the MAGT above $-1.5^{\circ} \mathrm{C}$ or $-1.0^{\circ} \mathrm{C}$, and permafrost has warmed during the last century (Farbrot et al., 2013). In the interior of Alaska, permafrost temperature has increased by $0.5^{\circ} \mathrm{C}-1.5^{\circ} \mathrm{C}$ during 1983-2003. On the Qinghai-Tibet Plateau, the increase rate of MAGT is about $0.012^{\circ} \mathrm{C}$ a-1 form 27 sites along Qinghai-Xizang (Tibet) Railway during 1996-2010, meanwhile, the variation in the thermal state of clod permafrost with a MAGT lower than $-1.0^{\circ} \mathrm{C}$ is more significant than that of warm permafrost ( $\mathrm{Wu}$ et al., 2012). MAGT in permafrost regions is a key parameter used to document changes of permafrost (IPCC, 2013), and also has significant implication on the distribution of ground and subsurface temperature. In general, the change in deep permafrost has a long response time, always requires several years or decades for permafrost to response to atmospheric warming or cooling (Haeberli et al., 1993). Snow cover, vegetable and soil moisture also have significant effect on permafrost thermal regime, due to the regional difference of these influential factors, it is difficult to analyze the permafrost thermal regime over the $\mathrm{NH}$ scale based on the observation from few stations.

In the global permafrost domain, ground temperature were to be measured in existing and new boreholes over a fixed time period in order to develop a snapshot of permafrost temperatures in both time and space. However, the long-term and continuous observation for permafrost is in its infancy. Hence, numerical simulation is the effective tool to study and project the changes in permafrost thermal regime.

Here, we mainly focus on the temporal and spatial changes in permafrost thermal regime and its relation with temperature during the different periods of the 21st century. The specific method and data are described in Section 2, and 
the temporal and spatial characteristics of permafrost thermal regimes are projected in Section 3, and the relation between permafrost thermal regime and temperature is discussed in Section 4. The results are given in Section 5.

\section{Data and Method}

To objectively quantify the change in permafrost thermal regime in the 21st century, six models (Table 1) from CMIP5 are chosen. The CMIP5 models' outputs include air temperature, snow depth, snow water equivalent and soil moisture in the historical experiments and different Representative Concentration Pathways (RCPs). The relevant information of the six models is given in Table 1. In the Historical experiment, the time series of output cover the period of 1850-2005, and 1986-2005 is regarded as the reference period. The simulation for three RCPs ranges from 2006 to 2100 , which is divided into three segments: early (2016-2035, EP), middle (2045-2065: MP) and late (2080-2099: LP) period.

In order to verify the performance of CMIP5 models, we also use the CRU air temperature and precipitation datasets, which covers the period of 1902-2012, and its spatial resolution is $0.5^{\circ} \times 0.5^{\circ}$. Soil moisture is from the Global Land Data Assimilation System (GLDAS), which including four layers: 0 - $10 \mathrm{~cm}, 10$ $40 \mathrm{~cm}, 40-100 \mathrm{~cm}$ and $100-200 \mathrm{~cm}$ (Rodell et al., 2004). The period of the time series is $1948-2012$, with a resolution of $0.5^{\circ} \times 0.5^{\circ}$, this dataset can be used as the observation (Zhu et al., 2014).

Studies suggested that Kudryavtsev's model is a well approaching for high quality estimating permafrost extent and active layer depth (Wang et al., 2014). In this paper, Kudryavtsev's model is used to estimate the permafrost extent. In this model, the soil texture (sand, silt, clay, and loam) data adopts the land surface module of Community Earth System Model (CESM), its resolution is $1.9^{\circ} \times$ $2.5^{\circ}$, and the value of the thermal properties of soil is from Anisimov et al. (1997). The vegetation parameters adopt the data used in GLDAS version 1, its resolution is $0.5^{\circ} \times 0.5^{\circ}$.

Due to the different resolution of the simulation and reanalysis data, a bilinear interpolation is used to make the reanalysis and models' datasets have a common $1^{\circ} \times 1^{\circ}$ latitude and longitude.

Table 1. Essential information of the 6 CMIP5 models used in this study.

\begin{tabular}{ccc}
\hline Model & Institution & Resolution \\
\hline CCSM4 & National Center for Atmospheric Research, USA & $1.25^{\circ} \times 0.94^{\circ}$ \\
CSIRO-Mk3-6-0 & CSIRO Atmospheric Research, Australia & $1.875^{\circ} \times 1.875^{\circ}$ \\
GFDL-CM3 & Geophysical Fluid Dynamics Laboratory, USA & $2.5^{\circ} \times 2.0^{\circ}$ \\
GISS-E2-R & NASA Goddard Institute for Space Studies, USA & $2.5^{\circ} \times 2.0^{\circ}$ \\
MIROC5 & Atmosphere and Ocean Research Institute, Japan & $1.4^{\circ} \times 1.4^{\circ}$ \\
MIROC-ESM & Japan Agency for Marine-Earth Science and Technology, & $2.8^{\circ} \times 2.8^{\circ}$ \\
& Atmosphere and Ocean Research Institute, Japan & \\
\hline
\end{tabular}


In this paper, we analyze the permafrost thermal regime by depth of zero annual amplitude (DZAA) and MAGT of permafrost thermal regime. DZAA is the level at where annual ground temperature variations diminish to less than $0.1^{\circ} \mathrm{C}$ (Williams \& Smith, 1989), namely, it also indicates the depth where annual wave of surface temperature caused by radiation heating is delayed by exactly one year from that at surface (Williams \& Smith, 1989), this is given by:

$$
\mathrm{DZAA}=2(\pi \kappa P)^{1 / 2}
$$

where $k$ is the soil thermal diffusivity $\left(\mathrm{m}^{2} / \mathrm{s}\right), P$ is the period of the wave of surface temperature (one year).

In a saturated system, thermal diffusivity, thermal conductivity and the volumetric heat capacity for a mixture of soil particles, unfrozen water, and ice are represented as (Williams \& Smith, 1989):

$$
\begin{gathered}
k=\frac{\lambda}{C} \\
\lambda \approx \lambda_{w}^{W_{u}} \cdot \lambda_{i}^{W-W_{u}} \cdot \lambda_{m}^{1-w} \\
C=C_{f}+L \cdot \rho_{d} \cdot \frac{\partial W_{u}}{\partial T} \\
C_{f}=C_{s f}+\left(W-W_{u}\right) C_{i}+W_{u} \cdot C_{u}
\end{gathered}
$$

$W$ is the total water content; $\lambda, \lambda_{w}, \lambda_{i}, \lambda_{m}$ are the thermal conductivity of the frozen soil, unfrozen water $\left(0.55 \mathrm{~W} \cdot \mathrm{m}^{-1} \cdot{ }^{\circ} \mathrm{C}^{-1}\right)$, ice $\left(2.22 \mathrm{~W} \cdot \mathrm{m}^{-1} \cdot{ }^{\circ} \mathrm{C}^{-1}\right)$ and minerals; $C, C_{f}, C_{s f}, C_{i}, C_{u}$ are the heat capacity of frozen soil, sensible heat capacity of the frozen soil, minerals, ice $\left(2.09 \mathrm{~kJ} \cdot \mathrm{m}^{-3} \cdot{ }^{\circ} \mathrm{C}^{-1}\right)$ and unfrozen water $(4.18$ $\left.\mathrm{kJ} \cdot \mathrm{m}^{-3} \cdot{ }^{\circ} \mathrm{C}^{-1}\right)$, respectively. $L$ is the volumetric latent heat of fusion for ice $(334.56$ $\left.\mathrm{kJ} \cdot \mathrm{m}^{-3}\right)$.

$$
W_{u}=a \cdot T^{-b}
$$

$W_{u}$ is the unfrozen water content, $T$ is the absolute value of negative temperature, $a$ and $b$ are the empirical coefficients according to the soil.

For permafrost, the general features of the thermal regime in the layer of annual variations, if the geothermal gradient term is ignored, the temperature at any depth, $Z$, can be calculated by (Ingersoll et al., 1954):

$$
T(z, t)=\overline{T_{x}}+A_{s} \mathrm{e}^{-z(\omega / 2 \kappa)^{1 / 2}} \sin \left[\omega \cdot t-\left(\frac{\omega}{2 \kappa}\right)^{1 / 2} \cdot z\right]
$$

In Equation (7), if $z$ is equal to the depth of zero annual amplitude, MAGT can be calculated by Equation (7).

\section{Simulation for Permafrost Thermal Regime}

\subsection{The Estimation for Permafrost Extent}

The Kudryavtsev's model has two major outputs: the depth of seasonal thawing and mean annual temperature at the depth of thawing, which can be used to de- 
finite whether the permafrost exists or not. If the temperature at the depth of thawing is negative at a grid, where the permafrost does exist.

To validate the performances of Kudryavtsev's model with CMIP5 simulation for estimating permafrost extent, the averaged permafrost extent over the Northern Hemisphere landmass during 1986-2005 is estimated by Kudryavtsev's model (Figure 1), combined with the simulated air temperature, snow depth, snow water equivalent and soil moisture from CMIP5 models. The black line is the $0^{\circ} \mathrm{C}$ isotherm of mean annual air temperature (MAAT). In general, the permafrost extent should be consistent with the $0^{\circ} \mathrm{C}$ isotherm of MAAT. Figure 1 shows that five of the six model well reproduce the permafrost extent, which agrees with the $0^{\circ} \mathrm{C}$ isotherm, however, the estimated extent from MIROCE-ESM is far away from the $0^{\circ} \mathrm{C}$ isotherm, this implies that there are larger biases between the inter-model, it also implies that the simulated results (temperature, snow depth, snow water equivalent etc.) have large uncertainly. The estimated permafrost area ranges from $13.8-21.0 \times 10^{6} \mathrm{~km}^{2}$ in 1986 to 11.1 - $16.8 \times 10^{6} \mathrm{~km}^{2}$ in 2005. After multi-model ensemble, the permafrost extent is not only in accordance with the $0^{\circ} \mathrm{C}$ isotherm, but also consistent with the permafrost extent estimated by Kudryavtsev's model with CRU data (Figure 2(a)), the time series of permafrost area during 1986-2005 from Figure 2(b) is well correlated with that from Figure 2(a), the correlation is 0.82 ( $\mathrm{P}>99.9 \%)$. The correlation between the time series of permafrost area in Figure 1 and that from Figure 2(a) ranges from 0.75 to 0.80 ( $\mathrm{P}>99.9 \%$ ). This implies that the multi-model ensemble can reduce the uncertainty of individual model, and improve the models' performance. In this paper, all simulation results denote the multi-model ensemble, and the analysis of permafrost thermal regime is conducted in the permafrost regions estimated by Kudryavtsev's model with the CMIP5 simulation in the historical and future emission scenarios (RCP2.6, RCP4.5 RCP8.5). In order to study the changes in permafrost thermal regime, the period of 1986-2005 in historical experiment (1850-2005) is regarded as the reference period.

\subsection{Changes in Permafrost Thermal Regimes over the Northern Hemisphere}

To analyze the temperature properties of permafrost, based on the Equations (1)-(7), DZAA is estimated at 13 observation sites located at permafrost region along the Qinghai-Tibet railway (Table 2). Compared with the observations, the multi-model ensemble overestimates at some sites, the relative error ratio (RE) ranges from $0.9 \%$ to $44.3 \%$. However, at three sites, such as QTB1, QTB5, QTB18, the simulation is very closer to the observation (RE less than 5\%), the errors at most sites is less than $30 \%$, only at three sites the RE exceeds $30 \%$, which implies Equations (1)-(7) fails to calculated the soil hydro-heat construct in some condition, which also implies that hydro-heat construct varies regionally in permafrost regions. In general, DZAA ranges from $10 \mathrm{~m}$ to $15 \mathrm{~m}$ over the 
TP (Zhou et al., 2000), and it may reach $3 \mathrm{~m}$ or less in the warm permafrost with the $-0.5^{\circ} \mathrm{C}$ mean annual surface temperature. Although the estimated DZAA is shallower than that reported by Zhou et al. (2000), the estimation is closer to the observation at most of the sites. Therefore, it is feasible to estimate DZAA based on the above equations.

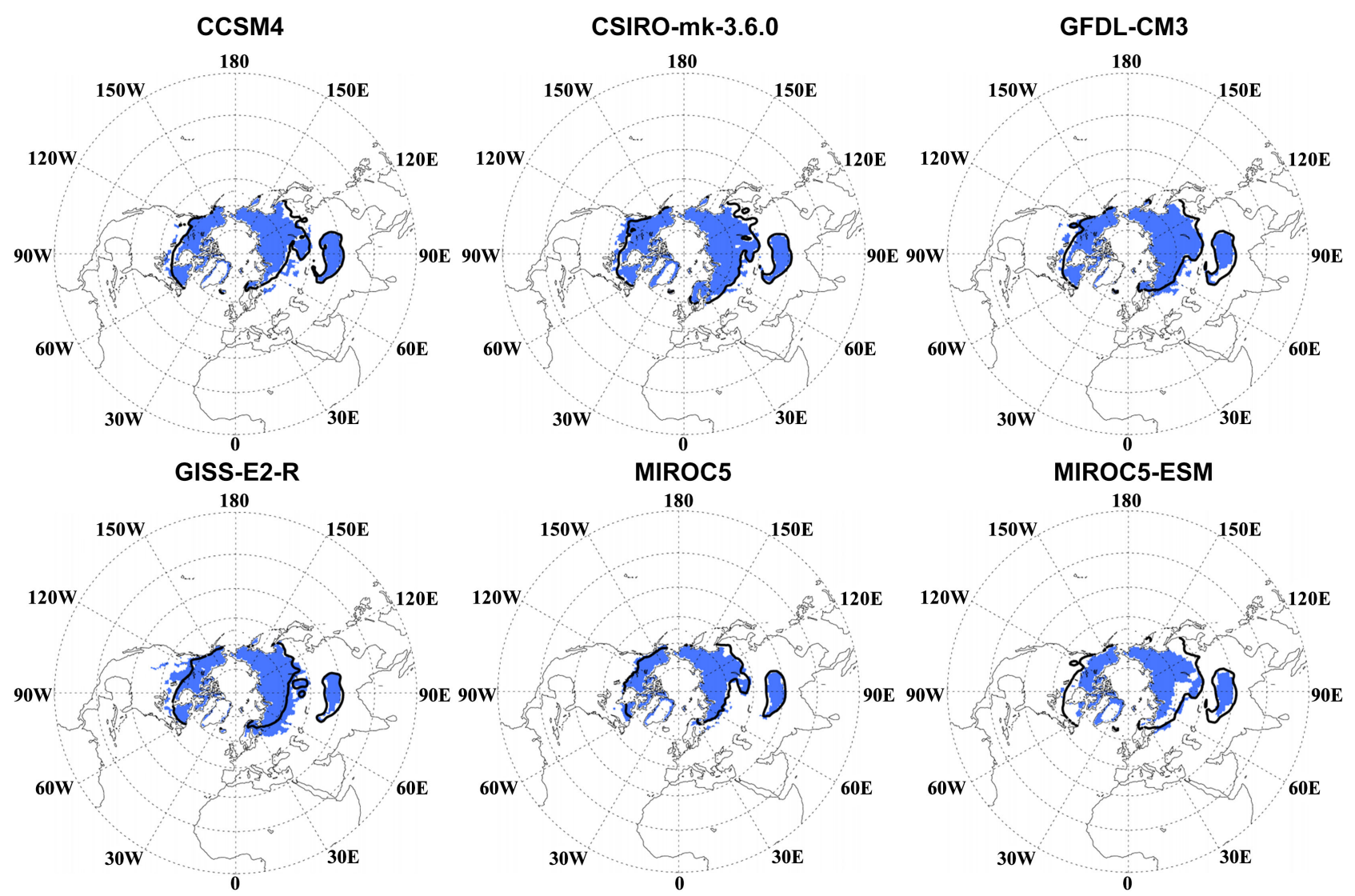

Figure 1. The averaged permafrost extent estimated by Kudryavtsev's model with six models from CMIP5 during the period of 1986-2005. The black lines indicate the $0^{\circ} \mathrm{C}$ isotherm of mean annual air temperature.

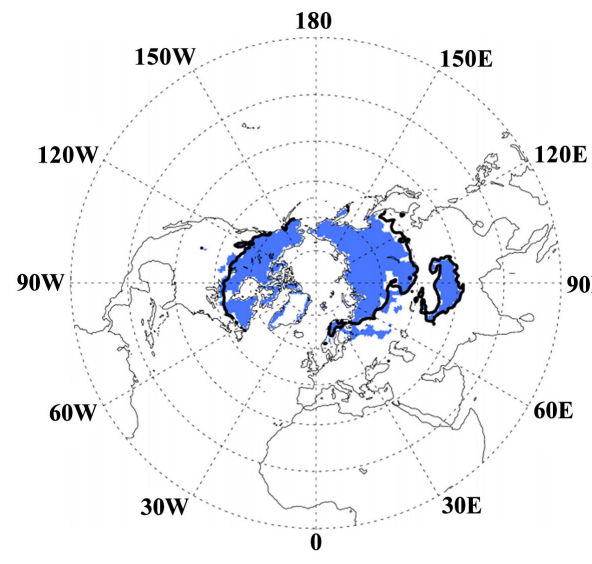

(a)

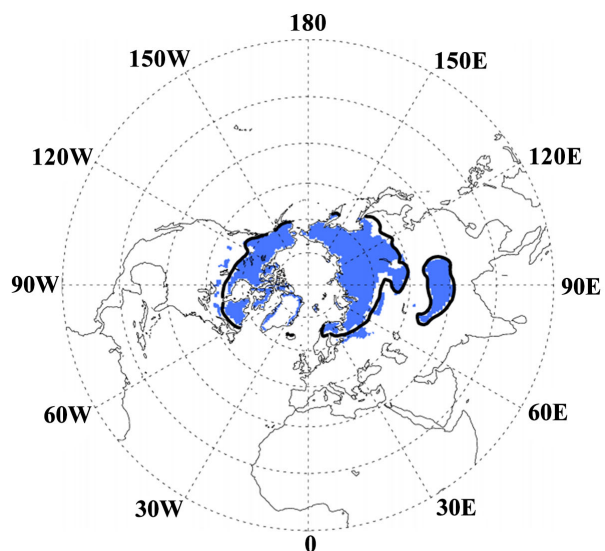

(b)

Figure 2. The averaged permafrost extent during the period of 1986-2005 estimated by Kudryavtsev's model with the reanalysis data (a) and multi-model ensemble (b). 
Table 2. The observed and simulated depth of zero annual amplitude (DZAA) along the Qinghai-Xizang (Tibet) Railway in 2010 (RE is the relative error ratio, Ensemble is the multi-model mean).

\begin{tabular}{ccccccc}
\hline & & \multicolumn{5}{c}{ DZAA } \\
\hline Sites & Lat & lon & $\begin{array}{c}\text { Altitude } \\
(\mathrm{m})\end{array}$ & $\begin{array}{c}\text { Ensemble } \\
(\mathrm{m})\end{array}$ & $\begin{array}{c}\text { Obs } \\
(\mathrm{m})\end{array}$ & RE (\%) \\
\hline QTB1 & $35^{\circ} 42^{\prime} 56^{\prime \prime} \mathrm{N}$ & $94^{\circ} 04^{\prime} 56^{\prime \prime} \mathrm{E}$ & 4230 & 6.5 & 6.4 & 1.5 \\
QTB2 & $35^{\circ} 37^{\prime} 32^{\prime \prime} \mathrm{N}$ & $94^{\circ} 03^{\prime} 34^{\prime \prime} \mathrm{E}$ & 4753 & 6.5 & 7.4 & -12.1 \\
QTB3 & $35^{\circ} 31^{\prime} 23^{\prime \prime} \mathrm{N}$ & $93^{\circ} 47^{\prime} 04^{\prime \prime} \mathrm{E}$ & 4560 & 4.55 & 3.8 & 19.7 \\
QTB4 & $35^{\circ} 25^{\prime} 50^{\prime \prime} \mathrm{N}$ & $93^{\circ} 36^{\prime} 01^{\prime \prime} \mathrm{E}$ & 4488 & 4.65 & 3.8 & 22.3 \\
QTB5 & $35^{\circ} 21^{\prime} 51 " \mathrm{~N}$ & $93^{\circ} 26^{\prime} 47^{\prime \prime} \mathrm{E}$ & 4520 & 7.77 & 7.7 & 0.9 \\
QTB6 & $35^{\circ} 17^{\prime} 24^{\prime \prime} \mathrm{N}$ & $93^{\circ} 16^{\prime} 08^{\prime \prime} \mathrm{E}$ & 4563 & 4.92 & 3.9 & 26.2 \\
QTB7 & $35^{\circ} 11^{\prime} 36^{\prime \prime} \mathrm{N}$ & $93^{\circ} 04^{\prime} 26^{\prime \prime} \mathrm{E}$ & 4656 & 8.53 & 6.8 & 25.4 \\
QTB9 & $35^{\circ} 07^{\prime} 59^{\prime \prime} \mathrm{N}$ & $93^{\circ} 01^{\prime} 59^{\prime \prime} \mathrm{E}$ & 4740 & 8.53 & 10.2 & -16.4 \\
BLH & $34^{\circ} 49^{\prime} 46^{\prime \prime} \mathrm{N}$ & $92^{\circ} 55^{\prime} 57^{\prime \prime} \mathrm{E}$ & 4621 & 8.95 & 6.8 & 31.6 \\
WULI & $34^{\circ} 28^{\prime} 39^{\prime \prime} \mathrm{N}$ & $92^{\circ} 43^{\prime} 33^{\prime \prime} \mathrm{E}$ & 4571 & 9.09 & 6.3 & 44.3 \\
KXL & $33^{\circ} 57^{\prime} 211^{\prime \prime} \mathrm{N}$ & $92^{\circ} 20^{\prime} 18^{\prime \prime} \mathrm{E}$ & 4726 & 9.25 & 6.5 & 42.3 \\
QTB18 & $31^{\circ} 49^{\prime} 07^{\prime \prime} \mathrm{N}$ & $91^{\circ} 44^{\prime} 12^{\prime \prime} \mathrm{E}$ & 4808 & 8.15 & 8.2 & -0.6 \\
\hline
\end{tabular}

The averaged MAGT of permafrost over the Northern Hemisphere land during the period of 1986-2005 is also estimated (figure is omitted). The multi-model ensemble results show that the MAGT has no significant changes in the south of Alaska, while a larger changes occurs in the north of Alaska, with a range of $-13^{\circ} \mathrm{C}$ to $-2^{\circ} \mathrm{C}$, which is consistent with the observation from IPA (Heginbottom et al., 1993) Over the TP, MAGT is larger than $-5^{\circ} \mathrm{C}$ in most permafrost regions, while in the central of TP, where the permafrost belongs to the cold permafrost, MAGT is lower than $-5^{\circ} \mathrm{C}$ (Zhang \& $\mathrm{Wu}, 2012$ ), which implies that the above equations can estimate MAGT well, and the multi-model ensemble can also reduce the uncertainty of the individual model. Hence, the analysis of hydro-heating regime in permafrost is based on the multi-model ensemble.

\subsection{The Projection for Permafrost Thermal Regime in the Future}

Permafrost is gradually warming and degenerating with the climate warming . Permafrost temperature is a key parameter to document changes of permafrost, in order to analyze the changes of the permafrost thermal regime in the future, Figure 3 shows the changes in MAGT of permafrost regions for three RCPs during the different periods, relative to the period of 1986-2005. In addition to some regions along the south limit of permafrost, an increase in MAGT in the permafrost regions is significantly stimulated throughout the 21st century. The increase in MAGT is less than $2.5^{\circ} \mathrm{C} \mathrm{RCP2.6,} \mathrm{and} \mathrm{the} \mathrm{changes} \mathrm{increase} \mathrm{in} \mathrm{mag-}$ nitude with time and emission concentration. The changes for RCP8.5 is significantly larger than that for RCP2.6 and RCP4.5, especially during the LP for $\mathrm{RCP} 8.5$, the increase in MAGT in most regions exceeds $4^{\circ} \mathrm{C}$. Obviously, a noti- 
ceable feature is that the most significant change in MAGT occurs in the cold permafrost (MAGT $<-2^{\circ} \mathrm{C}$ ) regions, mainly located in the northern Alaska, Canada arctic, Siberia and TP, where MAGT increases by about $4^{\circ} \mathrm{C}$ during the LP. However, it is note that the change in MAGT is less than $1^{\circ} \mathrm{C}$ at the south edge of high latitude permafrost. This implies that the changes in permafrost mainly depend in the cold permafrost in 21 st century.

In order to analyze thermal regime changes of permafrost with temperature increasing, Figure 4 shows the absolute changes in DZAA of permafrost in different periods and RCPs. Relative to the reference period of 1986-2005, a slight decrease in DZAA is also simulated during the three periods for RCP2.6, and the
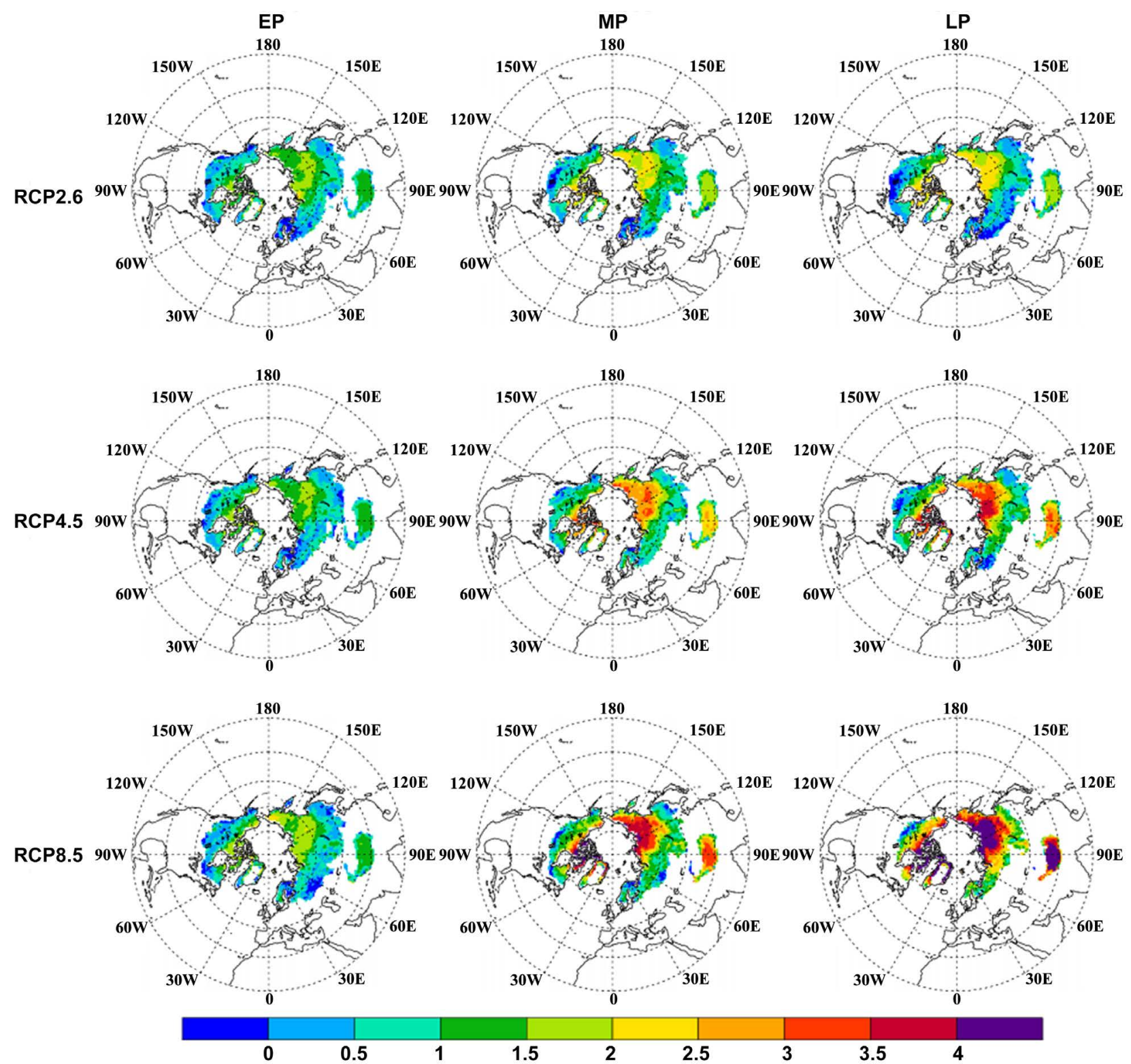

Figure 3. Spatial changes in mean annual ground temperature (MAGT, unit is ${ }^{\circ} \mathrm{C}$ ) for three RCPs during the 21 st century, relative to the reference period of 1986-2005 (EP, MP and LP are the periods of 2016-2035, 2046-2065, 2080-2099, respectively, the shaded portion is the persistent permafrost extent estimated by the Kudryavtsev's model). 

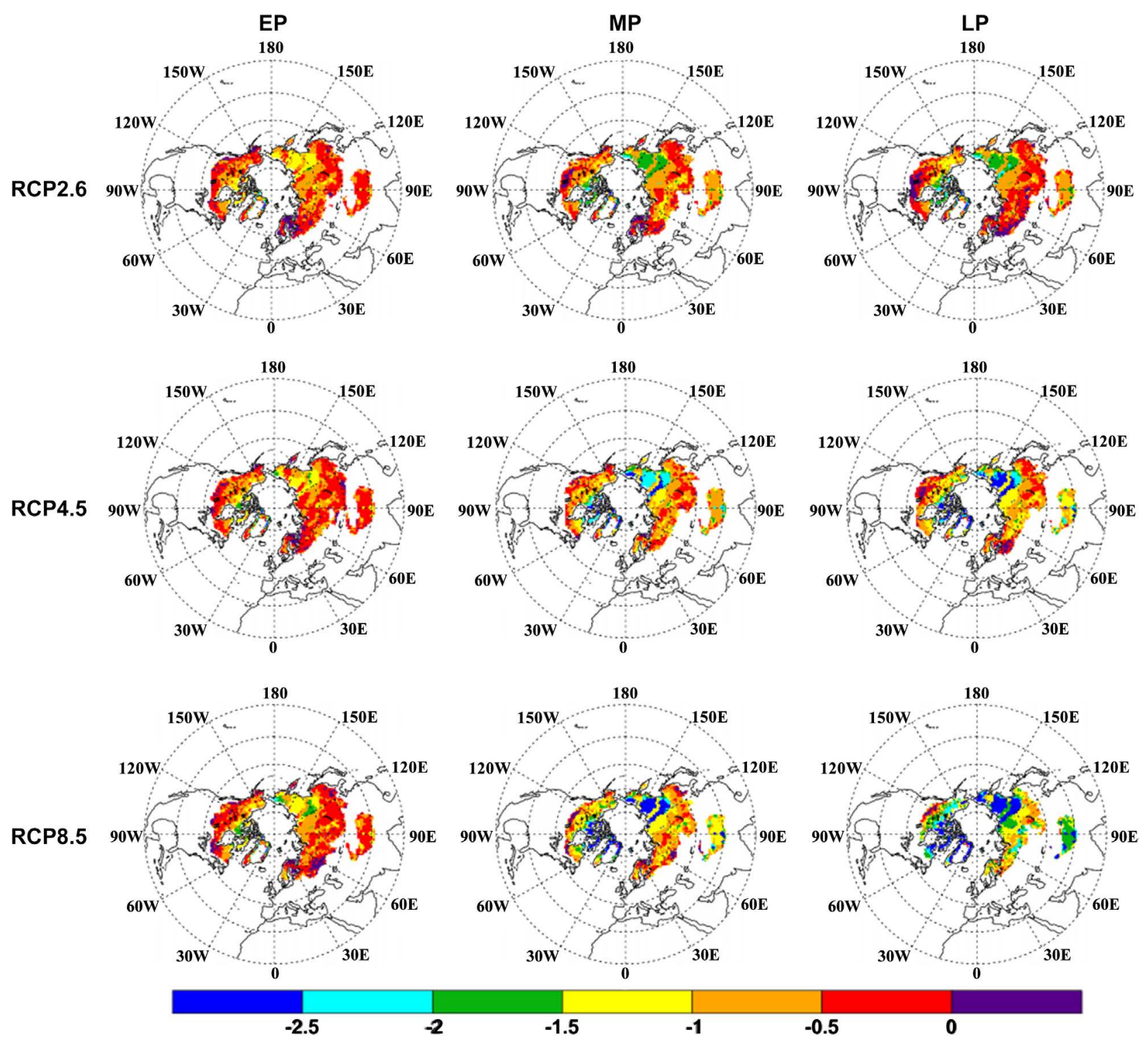

Figure 4. Spatial change of the depth of zero annual amplitude (DZAA, unit is $\mathrm{m}$ ) for three RCPs during the 21st century, relative to the reference period of 1986-2005 (EP, MP and LP are the same as in Figure 3, the shaded portion is the persistent permafrost extent estimated by the Kudryavtsev's model).

change grows larger with time and concentrations. During the LP, DZAA decreases by $2 \mathrm{~m}$ in Siberia Canada arctic and northern of North America, with a decrease of $1.5-2 \mathrm{~m}$ over the TP. The relative change in DZAA shows that the decrease in most permafrost regions exceeds $20 \%$, in most of Siberia area, the decrease is larger than $30 \%$ during the LP for RCP8.5 (not shown). Significantly, the largest change in DZAA also occurs in Siberia, Canada arctic, northern of North America and TP.

In order to further analyze the changes in permafrost thermal regime, the averaged ground temperature profiles in the permafrost regions over the Northern Hemisphere land for three RCPs are given in Figure 5. For the same scenario, the most significant change of DZAA and MAGT occurs during the LP, during 

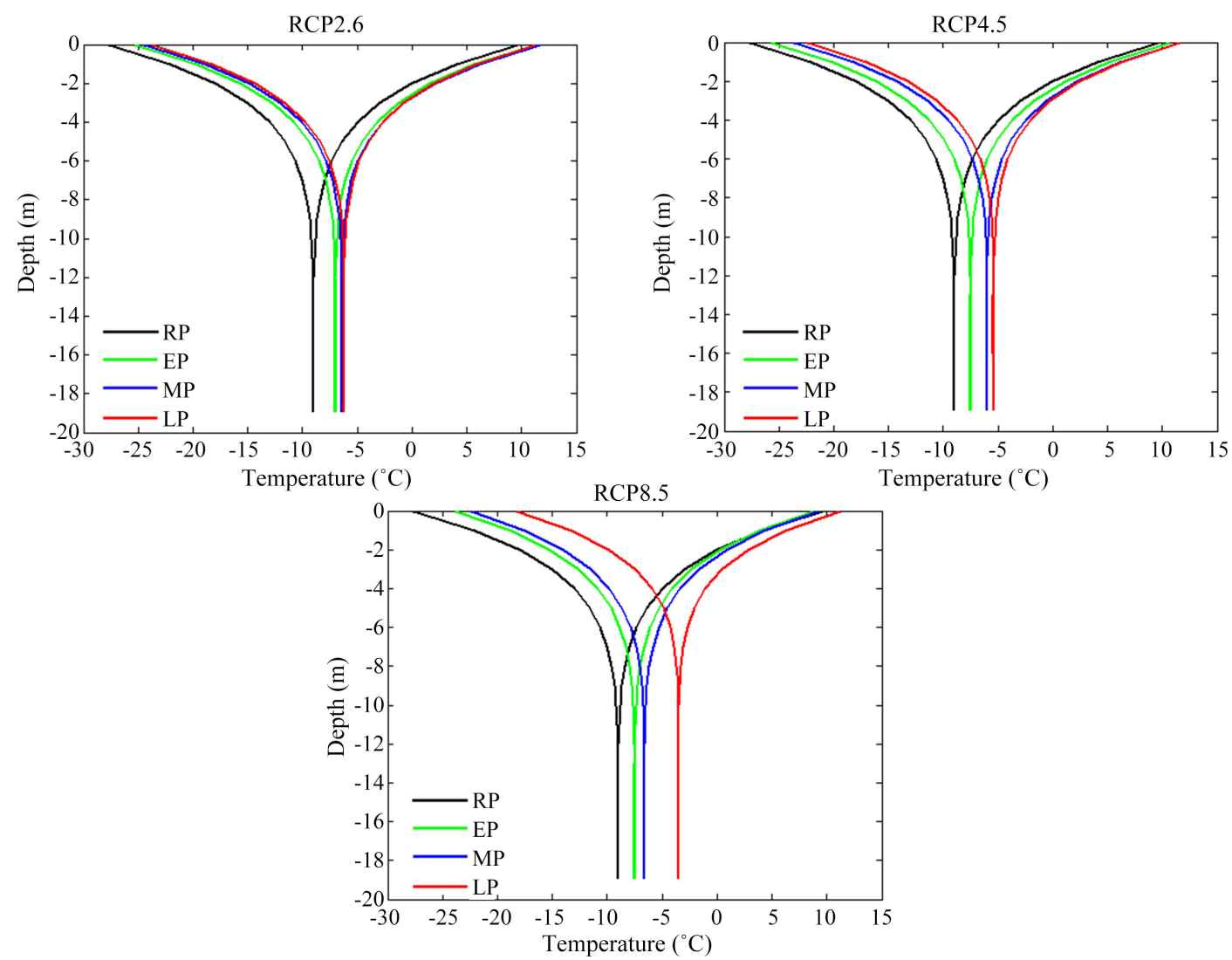

Figure 5. Changes in ground temperature profile of permafrost averaged over the Northern Hemisphere for three RCPs during the 21st century (RP indicates the period of 1986-2005, EP, MP and LP are the same as in Figure 3).

the same period, the change in DZAA and MAGT for RCP8.5 is larger than that for RCP2.6 and RCP4.5. Namely, the change in MAGT and DZAA increase in magnitude with time and emission concentrations. During the 1986-2005, the mean MAGT and DZAA over the Northern Hemisphere land are $-9.0^{\circ} \mathrm{C}$ and 12 $\mathrm{m}$, respectively, with the air temperature rising, DZAA gradually decrease from the RP, EP, MP to LP, and an increase in MAGT grows larger with time. During the $\mathrm{LP}$, the mean MAGT reaches $-3.5^{\circ} \mathrm{C}$, and DZAA reduces to $9 \mathrm{~m}$. The vertical temperature profile gradually moves to right, this implies the permafrost is warming with time.

In general, with the temperature rising, MAGT of permafrost gradually increase, and with a decrease trend of DZAA. However, the response of permafrost thermal regime to climate change varies regionally. The most significant change in MAGT and DZAA occurs in Alaska, Canada arctic, Siberia and TP. In order to analyze the response of permafrost thermal regime to climate warming, the linear trend of MAGT and DZAA in the whole permafrost regions, the warm and clod permafrost regions are shown in Table 3. Significantly, during the EP, over the $\mathrm{TP}$, the mean trend in the whole permafrost region is $0.31^{\circ} \mathrm{C} / 10 \mathrm{a}(\mathrm{P}>$ $90 \%)$, the trend of MAGT in the cold permafrost is $0.26^{\circ} \mathrm{C} / 10 \mathrm{a}(\mathrm{P}>90 \%)$, while in warm permafrost the trend is only $-0.01^{\circ} \mathrm{C} / 10 \mathrm{a}$, this implies that the change 
Table 3. The linear trend of mean annual ground temperature (MAGT) and the depth of zero annual amplitude (DZAA) under RCP8.5 during the 21st century (EP, MP and LP are the same as in Figure 3, Mean indicates the average in the whole permafrost regions, Warm and Cold are the averages in the warm and cold permafrost regions, respectively, $-2^{\circ} \mathrm{C}$ is the threshold of warm and cold permafrost).

\begin{tabular}{|c|c|c|c|c|c|c|c|c|c|c|}
\hline & \multicolumn{2}{|l|}{ Regions } & \multicolumn{3}{|c|}{ EP } & \multicolumn{3}{|c|}{ MP } & \multicolumn{2}{|c|}{ LP } \\
\hline & & Mean & Warm & Cold & Mean & Warm & Cold & Mean & Warm & Cold \\
\hline \multirow{4}{*}{$\begin{array}{c}\text { MAGT } \\
\left({ }^{\circ} \mathrm{C} / 10 \text { year }\right)\end{array}$} & $\mathrm{TP}$ & $0.31^{\star}$ & -0.01 & $0.26^{\star}$ & $0.31^{\star}$ & -0.02 & $0.32^{*}$ & $0.36^{\star}$ & -0.03 & $0.31^{\star}$ \\
\hline & Siberia & $0.63^{*}$ & 0.02 & $0.48^{\star}$ & $0.67^{\star}$ & 0.1 & $0.35^{\star}$ & 0.13 & -0.02 & 0.13 \\
\hline & Alaska & $0.24^{*}$ & 0.05 & $0.24^{\star}$ & 0.21 & -0.01 & 0.21 & 0.14 & -0.035 & 0.20 \\
\hline & Canada & $0.22^{\star}$ & 0.01 & $0.25^{\star}$ & 0.19 & 0.05 & 0.16 & 0.17 & 0.10 & 0.22 \\
\hline \multirow{4}{*}{$\begin{array}{c}\text { DZAA } \\
\text { (m/10year) }\end{array}$} & $\mathrm{TP}$ & $-0.35^{\star}$ & 0.01 & $-0.28^{\star}$ & $-0.36^{\star}$ & 0.03 & $-0.36^{*}$ & $-0.44^{*}$ & -0.03 & $-0.36^{\star}$ \\
\hline & Siberia & $-0.63^{\star}$ & -0.02 & $-0.54^{\star}$ & $-0.85^{\star}$ & -0.15 & $-0.28^{\star}$ & -0.18 & 0.15 & -0.13 \\
\hline & Alaska & $-0.41^{\star}$ & -0.07 & $-0.8^{*}$ & -0.19 & -0.04 & -0.20 & -0.19 & 0.06 & -0.19 \\
\hline & Canada & $-0.26^{\star}$ & -0.02 & $-0.28^{\star}$ & -0.26 & -0.05 & -0.19 & -0.23 & -0.12 & -0.18 \\
\hline
\end{tabular}

Note: ${ }^{*}$ indicates the trend exceeds $90 \%$ significant level.

of permafrost mainly depends on the cold permafrost. The similar characteristic also occurs in Siberia, Alaska and Canada. However, the significant trend of MAGT in Alaska and Canada does not keep during the MP and LP, this feature in Siberia disappears during the LP, only over the TP, the significant trend in MAGT persistently exists throughout the 21 st century. TP is the unique high altitude permafrost regions in the middle latitude of Northern Hemisphere, spatial geographical environment and climate condition make the permafrost thermal regime over the TP differ with that in other permafrost regions. With the global warming, permafrost is gradually warming, and turns into warm permafrost, even completely degenerate in most of permafrost region, this causes the trend gradually becomes insignificant. In the four permafrost regions, DZAA shows a decreasing trend, and the evolution of trend of DZAA is similar with that of MAGT. Moreover, the significant correlation $(>0.99)$ between DZAA and MAGT persistently exists throughout the 21st century, this implies that MAGT and DZAA synchronized accompany the climate warming.

\section{The Relation between Permafrost Thermal Regime and Temperature}

The most significant changes in DZAA and MAGT of permafrost occur at the high latitude and altitude, where temperature also has larger change, this suggests the changes in permafrost is likely to be related to the temperature increasing. In order to analyze the response of permafrost thermal regime to temperature rising, Table 4 shows the sensitivity of DZAA to air temperature for three RCPs during the 21st century. During 1986-2005, the sensitivity of DZAA to mean annual air temperature are $-0.93,-0.91,-0.83,-0.85 \mathrm{~m} /{ }^{\circ} \mathrm{C}$ on the TP, Siberia, Alaska and Canada. Obviously, the most significant response of perma- 
frost to temperature occurs in TP. In the four permafrost regions, the sensitivity of permafrost to temperature is significant throughout the 21st century. This implies that temperature may be the major influential factor for permafrost thermal regime. In the case of TP, Table 5 shows the correlation between MAGT and air temperature as well as that between DZAA and air temperature. The correlation between air temperature and MAGT does not be significant as expected except January. In different RCPs and periods, the significant correlation has randomness. However, the impact of temperature on permafrost thermal regime in January seems to reflect that the rate of increase in MAGT and decrease in DZAA gradually decrease, with the air temperature increasing.

Table 4. The relationship between the depth of zero annual amplitude (DZAA) and air temperature during the 21st century (RP indicates the period of 1986-2005, EP, MP and LP are the same as in Figure 3).

\begin{tabular}{ccccccccccc}
\hline & \multicolumn{3}{c}{ RCP2.6 } & \multicolumn{3}{c}{ RCP4.5 } & \multicolumn{3}{c}{ RCP8.5 } \\
\hline Regions & RP & EP & MP & LP & EP & MP & LP & EP & MP & LP \\
\hline TP & -0.93 & -0.91 & -0.88 & -1.04 & -0.90 & -0.97 & -0.98 & -0.90 & -0.93 & -0.99 \\
& -0.91 & -0.97 & -0.88 & -0.96 & -0.92 & -0.93 & -0.85 & -0.94 & -0.98 & -0.64 \\
\hline \multirow{2}{*}{ Siberia } & -0.83 & -0.82 & -0.68 & -1.01 & -0.85 & -0.82 & -0.81 & -0.84 & -0.93 & -0.62 \\
& -0.85 & -0.76 & -0.90 & -0.86 & -0.75 & -0.78 & -0.80 & -0.87 & -0.90 & -0.83 \\
\hline \multirow{2}{*}{ Alaska } & 0.86 & 0.81 & 0.78 & 0.91 & 0.80 & 0.84 & 0.80 & 0.80 & 0.80 & 0.80 \\
& 0.82 & 0.87 & 0.77 & 0.86 & 0.81 & 0.78 & 0.66 & 0.90 & 0.79 & 0.15 \\
\hline Canada & 0.71 & 0.67 & 0.53 & 0.80 & 0.67 & 0.63 & 0.66 & 0.56 & 0.67 & 0.25 \\
& 0.74 & 0.64 & 0.76 & 0.76 & 0.64 & 0.67 & 0.62 & 0.75 & 0.72 & -0.67 \\
\hline
\end{tabular}

Table 5. The correlation between mean annual ground temperature (MAGT) and air temperature as well as that between the depth of zero annual amplitude (DZAA) and air temperature over the TP during the RP, EP, MP and LP (RP indicates the period of 1986-2005, EP, MP and LP are the same as in Figure 3).

\begin{tabular}{ccccccccccccc}
\hline & & \multicolumn{3}{c}{ RCP2.6 } & \multicolumn{3}{c}{ RCP4.5 } & \multicolumn{3}{c}{ RCP8.5 } \\
\cline { 3 - 11 } & & RP & EP & MP & LP & EP & MP & LP & EP & MP & LP \\
\hline \multirow{2}{*}{ Jan } & MAGT & $0.72^{*}$ & $0.59^{*}$ & $0.64^{*}$ & $0.72^{*}$ & $0.62^{*}$ & $0.64^{*}$ & 0.34 & $0.69^{*}$ & $0.63^{*}$ & 0.25 \\
& DZAA & $-0.61^{*}$ & $-0.45^{*}$ & $-0.51^{*}$ & $-0.59^{*}$ & $-0.53^{*}$ & $-0.45^{*}$ & -0.27 & $-0.56^{*}$ & $-0.42^{*}$ & -0.07 \\
\hline \multirow{2}{*}{ Feb } & MAGT & -0.06 & -0.07 & -0.15 & 0.24 & 0.04 & 0.27 & -0.08 & 0.35 & $0.47^{*}$ & -0.23 \\
& DZAA & 0.08 & 0.08 & 0.17 & -0.21 & 0.07 & -0.3 & 0.15 & -0.28 & -0.23 & $0.39^{*}$ \\
\hline \multirow{2}{*}{ Mar } & MAGT & 0.12 & 0.07 & 0.23 & 0.20 & 0.13 & $-0.37^{*}$ & -0.26 & -0.17 & 0.1 & 0.35 \\
& DZAA & -0.15 & 0.14 & -0.24 & -0.25 & -0.14 & 0.15 & 0.27 & 0.12 & 0.06 & -0.25 \\
\hline \multirow{2}{*}{ Apr } & MAGT & -0.35 & $-0.36^{*}$ & 0.14 & -0.04 & 0.15 & -0.03 & $-0.47^{*}$ & 0.15 & -0.05 & $-0.38^{*}$ \\
& DZAA & 0.30 & $0.36^{*}$ & $-0.38^{*}$ & 0.04 & -0.05 & -0.17 & 0.47 & -0.23 & 0.28 & $0.5^{*}$ \\
\hline \multirow{2}{*}{ May } & MAGT & -0.28 & -0.21 & 0.41 & -0.22 & -0.08 & -0.1 & $-0.56^{*}$ & $0.41^{*}$ & 0.26 & -0.22 \\
& DZAA & $0.38^{*}$ & 0.19 & $-0.48^{*}$ & 0.14 & -0.01 & -0.03 & $0.52^{*}$ & $-0.39^{*}$ & 0.07 & 0.18 \\
\hline
\end{tabular}




\section{Continued}

\begin{tabular}{cccccccccccc}
\hline \multirow{2}{*}{ Jun } & MAGT & 0.06 & 0.32 & 0.08 & -0.10 & -0.25 & -0.23 & 0.03 & $0.38^{*}$ & 0.13 & -0.04 \\
& DZAA & 0.09 & -0.03 & -0.14 & 0.12 & 0.29 & 0.19 & -0.05 & -0.35 & 0.07 & 0.18 \\
\hline \multirow{2}{*}{ Jul } & MAGT & 0.19 & -0.02 & 0 & $-0.42^{*}$ & -0.06 & 0.28 & -0.24 & 0.4 & 0.22 & 0.15 \\
& DZAA & -0.05 & 0.05 & -0.04 & $0.37^{*}$ & 0.1 & -0.2 & $0.37^{*}$ & -0.3 & -0.19 & 0.05 \\
\hline \multirow{2}{*}{ Aug } & MAGT & $0.42^{*}$ & 0.19 & $0.48^{*}$ & 0.14 & 0.13 & 0.37 & 0.15 & $0.43^{*}$ & 0.1 & 0.04 \\
& DZAA & -0.27 & -0.18 & $-0.52^{*}$ & -0.22 & -0.11 & $-0.41^{*}$ & -0.07 & -0.28 & 0.08 & 0.09 \\
\hline \multirow{2}{*}{ Sep } & MAGT & 0.07 & -0.01 & -0.02 & -0.03 & 0.11 & 0.18 & -0.15 & 0.8 & 0.16 & 0 \\
& DZAA & -0.18 & -0.08 & -0.1 & 0.03 & -0.09 & -0.25 & 0.1 & $-0.67^{*}$ & 0.03 & 0.22 \\
\hline \multirow{2}{*}{ Oct } & MAGT & 0.01 & 0.13 & 0.28 & 0.07 & 0.3 & 0.17 & 0.03 & 0.43 & 0.23 & -0.01 \\
& DZAA & -0.18 & 0.13 & -0.29 & -0.15 & -0.37 & -0.09 & 0.01 & -0.4 & 0.03 & 0.21 \\
\hline \multirow{2}{*}{ Nov } & MAGT & 0.20 & $0.39^{*}$ & 0.07 & -0.08 & 0.12 & 0.23 & -0.3 & $0.65^{*}$ & 0.21 & 0.15 \\
& DZAA & -0.19 & -0.35 & -0.26 & -0.02 & -0.11 & -0.19 & 0.23 & $-0.49^{*}$ & -0.08 & 0.06 \\
\hline \multirow{2}{*}{ Dec } & MAGT & $0.37^{*}$ & 0.07 & 0.11 & 0.12 & $0.38^{*}$ & 0.33 & -0.19 & $0.66^{*}$ & 0.29 & 0.26 \\
& DZAA & -0.26 & 0.01 & -0.13 & -0.07 & $-0.39^{*}$ & $-0.43^{*}$ & 0.2 & $-0.57^{*}$ & -0.01 & -0.06 \\
\hline
\end{tabular}

Note: ${ }^{*}$ indicates the correlation passes the $90 \%$ significant level.

\section{Conclusion}

Based on the CMIP5 stimulation and numerical models, the permafrost thermal regime over the Northern Hemisphere land in the 21st century is projected, and the relation between permafrost thermal regime and temperature is also analyzed. The main conclusions are as follows:

Relative to the reference period of 1986-2005, permafrost thermal regime has significant change in the 21st century. MAGT shows an increasing trend, while DZAA has a decreasing trend, and the most significant changes occur in the northern Alaska, Canada arctic, Siberia and TP. While at the south edge of permafrost, permafrost has no significant changes, where the permafrost belongs to the warm permafrost, and its response to climate change is less significant than that of cold permafrost.

In Alaska, Canada arctic, Siberia and TP, the changes in permafrost mainly depend on the cold permafrost. Over the TP, the significant increase in MAGT and decrease in DZAA persistently exist from the EP to LP. In Siberia, the most significance of MAGT and DZAA only occurs during the EP and MP. In Alaska and Canada, permafrost has significant changes only in the EP, this implies that permafrost will turn into warm permafrost or gradually degenerate after the MP in the high latitude, namely, the response of permafrost in high latitude to climate is larger than that at the high altitude.

The change of permafrost thermal regime is mainly related to air temperature rising in winter, especially in January. However, relative to the reference period of 1986-2005, the sensitivity of permafrost to temperature gradually decreases, which means that the rate of DZAA reduction or MAGT increase will gradually 
decline, with the temperature increasing. That is to say, there is a threshold for the relation between MAGT and temperature as well as that between DZAA and temperature, if this threshold is exceeded, the impact of temperature on MAGT and DZAA will gradually decrease during the 21 st century.

\section{Acknowledgements}

This work is funded by the Undergraduate Teaching Engineering of Chengdu University of Information Technology (BKJX2020057, JYJG2021034).

\section{Conflicts of Interest}

The authors declare no conflicts of interest regarding the publication of this paper.

\section{References}

Drozdov, D. S., Ukraintseva, N. G., Tsarev, A. M. et al. (2010). Changes in the Temperature Field and in the State of the Geosystems within the Territory of the Urengoy Field during the Last 35 Years (1974-2008). Earth Cryosphere, 14, 22-31.

Farbrot, H., Isaksen, K., Etzelmüller, B. et al. (2013). Ground Thermal Regime and Permafrost Distribution under a Changing Climate in Northern Norway. Permafrost and Periglacial Processes, 24, 20-38. https://doi.org/10.1002/ppp.1763

Haeberli, W., Cheng, G., Gorbunov, A. P. et al. (1993). Mountain Permafrost and Climatic Change. Permafrost and Periglacial Processes, 4, 165-174.

https://doi.org/10.1002/ppp.3430040208

Heginbottom, J. A., Broen, J., Melnikov, E. S. et al. (1993). Circum-Arctic Map of Permafrost and Ground Ice Conditions. In Proceedings of the Sixth International Conference on Permafrost (pp. 1132-1136). South China University of Technology Press.

Ingersoll, L. R., Zobel, O. J., \& Ingersoll, A. C. (1954). Heat Conduction with Engineering, Geological and Other Applications (325 p). McGraw-Hill.

IPCC (2013). Climate 2013: The Scientific Basis. Observed Cryosphere (p. 362). Cambridge University Press.

Ling, F., \& Zhang, T. J. (2003). Numerical Simulation of Permafrost Thermal Regime and Talik Development under Shallow Thaw Lakes on the Alaskan Arctic Coastal Plain. Journal of Geophysical Research, 108, 4511. https://doi.org/10.1029/2002JD003014

Nelson, F. E., Brigham, L. W., Hinkel, K. M. et al. (2003). Climate Change, Permafrost, and Infrastructure Impacts. US Arctic Research Commission, Permafrost Task Force Report. 64.

Oberman, N. G. (2008). Contemporary Permafrost Degradation of the European North of Russia. In D. L. Kane, \& K. M. Hinkel (Eds.), Proceedings of the Ninth International Conference on Permafrost (pp. 1305-1310). Institute of Northern Engineering, University of Alaska Fairbanks.

Osterkamp, T. E. (2005). The Recent Warming of Permafrost in Alaska. Global Planet Change, 49, 187-202. https://doi.org/10.1016/j.gloplacha.2005.09.001

Qin, D. H., Liu, S. Y., \& Li, P. J. (2006). Snow Cover Distribution, Variability, and Response to Climate Change in Western China. Journal of Climate, 19, 1820-1833. https://doi.org/10.1175/JCLI3694.1

Rodell, M., Houser, P. R., Janmbor, U. et al. (2004). The Global Land Data Assimilation 
System. Bulletin of the American Meteorological Society, 85, 381-394. https://doi.org/10.1175/BAMS-85-3-381

Romanovsky, V. E., Drozdov, D. S., \& Oberman, N. G. (2010). Thermal State of Permafrost in Russia. Permafrost and Periglacial Process, 21, 136-155.

https://doi.org/10.1002/ppp.683

Romanovsky, V. E., Gruber, S., Instanes, A. et al. (2007). Frozen Ground Chapter 7. In Global Outlook for Ice and Snow (pp. 181-200). United Nations Environment Programme/GRID.

Wang, C. H., Jin, S. L., \& Shi, H. X. (2014). Area Change of the Frozen Ground in China in the Next 50 Years. Journal of Glaciology and Geocrylolgy, 36, 1-8. (In Chinese)

Williams, P. J., \& Smith, M. W. (1989). The Frozen Earth: Fundamentals of Geocryology. Cambridge University Press. https://doi.org/10.1017/CBO9780511564437

Wu, Q., Zhang, T., \& Liu, Y. (2012). Thermal State of the Active Layer and Permafrost along the Qinghai-Xizang (Tibet) Railway from 2006 to 2010. The Cryosphere, 6, 607-612. https://doi.org/10.5194/tc-6-607-2012

Zhang, Z. Q., \& Wu, Q. B. (2012). Predicting Changes of Active Layer Thickness on the Qinghai-Tibet Plateau as Climate Warming. Journal of Glaciology and Geocryology, 34, 505-511. (In Chinese)

Zhou, Y. W. et al. (2000). Frozen Ground in China. Science Press.

Zhu, Z., Shi, C. X., \& School, R. S. (2014). Simulation and Evaluation of CLDAS and GLDAS Soil Moisture Data in China. Science Technology \& Engineering, 14, 138-144. (In Chinese)

Zimov, S., Schuur, E., \& Chapin, F. (2006). Permafrost and the Global Carbon Budget. Science, 312, 1612-1613. https://doi.org/10.1126/science.1128908 